\title{
Curtailment of higher surgical training in the UK: likely effects in otology
}

\author{
J Ray PhD FRCS(Orl) E Hadjihannas MRCS R M Irving MD FRCS
}

\section{SUMMARY}

Higher surgical training in the UK faces a cut of two years. We conducted a questionnaire survey to assess the operative experience of current higher surgical trainees in otological surgery and the likely effect of the proposed reduction from six to four years.

$91(65 \%)$ of the 142 higher surgical trainees responded with details of major otological procedures performed (independently or assisting) over one year. In the present six-year scheme a typical trainee performs 72 myringoplasties, 79 mastoidectomies, 7 skull base procedures and 28 other procedures. In the first four years, however, his or her experience is only 39 myringoplasties, 44 mastoidectomies, 4 skull base procedures and 7 others.

The large shortfall in experience that might result from shortening of the training programme would need to be met by intensification of the training or institution of accredited otology fellowships. Very similar dilemmas are faced by other surgical specialties.

\section{INTRODUCTION}

Surgical training in the UK, as in most parts of the world, has been made up of cumulative experience through mentorship and apprenticeship. The first major change came with the introduction of the Calman reforms in 1995. This was intended to allow a smooth transition between the junior and senior training grades and to ensure a uniform standard of training across the country. This also brought about a slight reduction in the overall training period for most trainees and there were concerns in many quarters about the competencies of the products of the new system. ${ }^{1-5}$ When the first batch of Calman trainees were interviewed $^{6} 39 \%$ perceived gaps in their clinical training. Higher surgical training in the UK now faces curtailment not only through a proposed two-year cut in duration but also through the effects of the European Working Time Directive. ${ }^{1}$ Other adverse influences are waiting time pressures and the loss of potential training material to independent diagnostic and treatment centres.

We examined the possible impact of the proposed twoyear cut in otology training.

Department of Otolaryngology, University Hospital Birmingham, Edgbaston, Birmingham B15 2TH, UK

Correspondence to: J Ray, 4 Wentworth Park Avenue, Harborne, Birmingham B17 9QU, UK

E-mail: jaydip@bigfoot.com

\section{METHODS}

In November 2002 a piloted confidential postal questionnaire was sent out to 142 higher surgical trainees in otolaryngology in England, Wales and Scotland. Their names and addresses were obtained from the database of ENT UK. Prepaid envelopes were provided and the survey was conducted in two rounds. Respondents were asked for details of major otological procedures performed in one academic year from 1 October 2001 to 1 October 2002. They also recorded their training region (deanery), year of training and type of hospital (teaching/district general). Categories of operations were recorded as recommended in the curriculum set by the Joint Committee on Higher Surgical Training-namely, myringoplasty, cortical mastoidectomy, canal wall down, canal wall up (combined approach tympanoplasty), other major otological procedures (cochlear implants, stapedectomy, ossiculoplasty, osteomas, sac surgery, labyrinthectomy) and skull base procedures (acoustic neuromas, facial nerve surgery, glomus tumours, petrosectomy, cancer surgery). The role of the trainee in the operations (main surgeon or assistant) was also recorded.

\section{RESULTS}

142 higher surgical trainees in otolaryngology were surveyed through piloted prepaid postal questionnaires and the final response rate was 91 (65\%). Respondents 


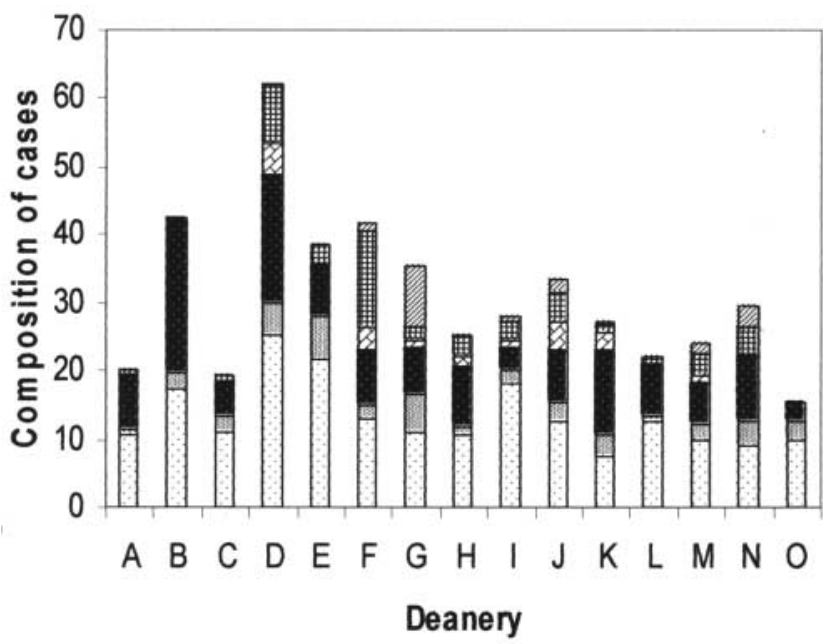

Figure 1 Otologic case mix in different deaneries. $\mathrm{A}-\mathrm{O}$, deaneries. Type of operations: skull base; 娄 other; 圈 canal wall up; canal wall down; cortical; [myringoplasty

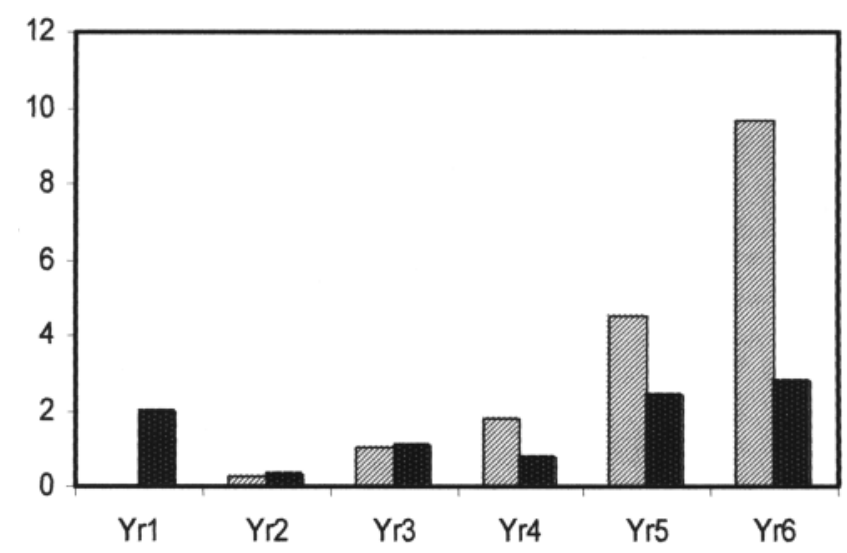

Figure 2 Change in proportion assistant and main surgeon in other otological procedures. main surgeon; assistant

were well distributed geographically and the numbers in the six training years were about equal.

By the end of six years of higher surgical training in otolaryngology a trainee will have performed on average 72 myringoplasties, 79 mastoidectomies (cortical 18; modified radical 49; combined approach 12), 7 skull base procedures and 28 miscellaneous procedures including cochlear implants, stapedectomy, ossiculoplasty, osteomas, sac surgery, labyrinthectomy. However in the first four years only the following numbers are reached: 39 myringoplasties, 44 mastoidectomies (cortical 14; modified radical 24; combined approach 6), 4 skull base and 7 others. This represents a statistically significant shortfall $(P<0.05$, Wilcoxon Rank sum).

The nature of surgical experience varies greatly between regions. For example, the average annual number of myringoplasties can range from 7 to 25 while the number of
For more specialized procedures such as combined approach tympanoplasty the exposure can range from 0 to 5 cases per year (depending on whether there is a surgeon in that region performing the procedure). This regional casemix variation is illustrated in Figure 1. Almost half of the total surgical training experience is gained in the final two years of training. The first three years involve more assisting while the later years see more independent operating (Figure 2).

\section{DISCUSSION}

Over the last two decades a lot of thought has been given to apprenticeship, fellowship and subspecialty acceditation in otology and neurotology. ${ }^{7}$ In the UK, with the rapidly changing medical climate, such issues become more pertinent because of their medicolegal implications throughout the future surgical career of trainees. One factor blamed for poor results from training is a reduction in number of procedures performed, ${ }^{8,9}$ and it has been suggested that trainees not wishing to undertake a certain procedure should turn over those cases to fellow trainees keen to take up that procedure. ${ }^{10}$ Fellowship training is another option. ${ }^{11}$ Schucknecht ${ }^{12}$ has suggested separation of training into otology and head and neck so as to save the chronic otitis media and otosclerosis cases for those who wish to pursue that aspect of otolaryngology as their career.

The changing outlook and expectations of the current trainees also has an impact on how training is delivered. In a recent survey only $15.4 \%$ of the UK specialist registrars in otolaryngology wished to pursue a subspecialized career pathway though about $71 \%$ wished to be a generalist with a special interest. ${ }^{13}$ Although a reduction in higher surgical training may suit the generalist, further training will be essential for those who want to pursue a subspecialist interest. In one survey, ${ }^{14}$ reasons for pursuing subspecialty fellowships were 'inadequate training during training', 'personal interest' and 'increased marketability'.

If the training period is reduced to four years it will need to be intensified to make up the shortfall in operative experience, and a training curriculum needs to be considered. Of programme directors in US radiology residency programmes, more than three-quarters wanted national curriculum guidelines. ${ }^{15}$ It will also have to be strictly monitored through procedures that reflect competence.

Our concerns about training in otology echo those expressed in other specialities - in this Journal most recently by senior house officers in ophthalmology. ${ }^{16}$ In the USA most programme directors and chief residents of general surgical residency programmes believe the most important aspect of training to be the acquisition of surgical judgment and skill, and favour a more structured approach in the 
technical aspects. The need for an adequate number of surgical procedures to reach competency is a recurring theme in most surgical subspecialties. ${ }^{14,17}$

Reduction in training in otologic surgery from six to four years will substantially reduce surgical experience. To maintain current high standards of training this shortfall needs to be made up either by intensifying the shorter training or by setting up accredited otology fellowship centres for prospective otologists.

Acknowledgment We thank Ms Barbara Komoniewska of ENT UK for help with the survey and Yen Chuah for statistical advice.

\section{REFERENCES}

1 Bourne MC, Paterson-Brown. Calman and the new dealcompromising doctor training and patient care. Scott Med J 1999;44:147-8

2 Skidmore FD. Junior surgeons are becoming deskilled as result of Calman proposals. BMJ 1997;314:1281

3 Bagley JS. The problems of surgeons in training. $J$ R Coll Surg Edinb 1996;41:206-7

4 Collins RE. Surgeons and the new deal-good deal or raw deal? Ann $R$ Coll Surg Engl 1995;77(6 suppl):297-8

5 Wrede D. Implementing Calman: the trainees' viewpoints. Med Educ 1994;28(suppl 2):22-4
6 Baldwin PJ. Higher specialist training - teething problems. Working Minds Research Project. Health Bull (Edinb) 1999;57:300-11

7 Gantz BJ. Fellowship training in neurotology. Otol Neurotol 2002;23:623-30

8 Backhouse DD, Coker NJ, Jenkins HA. Prospective study of resident performed stapedectomy. Am J Otol 1993;14:451-4

9 Levenson MJ, Belluci RJ, Grimes C, Ingerman M, Parisier SC. Otosclerosis surgery in a residency training programme. Arch Otolaryngol Head Neck Surg 1987;113:29-31

10 Levenson MJ. Methods of teaching stapedectomy. Laryngoscope 1999; 109:1731-9

11 Graham MD. Residency and fellowship in otology, neurotology and skull base surgery within an academic department of otolaryngology. Am J Otol 1984;5:229-32

12 Schuknecht HF. Training in otolaryngology. Arch Otolaryngol 1979; 105:57

13 Sandhu GS, Frosh AC, Jefferis AF. Specialist registrars in otolaryngology: their training programme and training aspirations. Clin Otolaryngol 2001;26:221-6

14 Lee TT, Klose JL. Survey of neurosurgery subspeciality fellowship training. Congress of Neurosurgical Surgeons Education Committee. Surg Neurol 1999;52:641-5

15 Gay SB, Talner LB, Hunt RK, Mclllhenny J, Smith WL, Arndt JH. Current status of residency programmes: survey of programme directors. Acad Radiol 1995;2:254-9

16 Watson MP, Boulton MG, Gibson A, Murray PI, Moseley MJ, Fielder AR. The state of basic surgical training in the UK: ophthalmology as a case example. J R Soc Med 2004;97:174-8

17 Ricci M, Karmanoukian HL, D’Ancona G, et al. Survey of resident training in beating heart operations. Ann Thoracic Surg 2000;70 479-82 